\title{
Update on diabetes mellitus
}

\author{
Murray Korc \\ Division of Endocrinology, Departments of Medicine, and Pharmacology and Toxicology, Dartmouth-Hitchcock \\ Medical Center and Dartmouth Medical School, Hanover, NH, USA
}

\begin{abstract}
Diabetes mellitus is a complex multi-system disorder that may be classified as autoimmune mediated type 1 diabetes, or as insulin resistance associated type 2 diabetes. In type 1 diabetes, there is selective loss of the beta cells within the endocrine islets, as a consequence of T-cell and cytokine mediated destruction of these cells, perhaps in conjunction with destruction of the peri-islet Schwann cells. In type 2 diabetes, the etiology of the resistance ranges from post-receptor defects in the insulin signaling pathway to excessive production of adipocyte derived cytokines that antagonize insulin action to mitochondrial defects that interfere with glucose disposal. Proteome based technologies are providing new insights into these defects.
\end{abstract}

Keywords: Beta cell, insulin resistance, mitochondrial defects, pancreatic cancer

\section{Introduction}

Diabetes mellitus afflicts 6 to $8 \%$ of the population in the US. Type 1 diabetes mellitus (T1DM) patients have lost their beta cells as a result of aberrant activation of cellular immune mechanisms, and they no longer produce insulin. They are dependent, therefore, on insulin injections for survival. Most individuals with diabetes have type 2 diabetes mellitus (T2DM) and are resistant to insulin action. $\mathrm{T} 2 \mathrm{DM}$ is also associated with beta cell dysfunction, and with production of fatderived cytokines that antagonize insulin actions. This review will focus on several recent developments in T1DM and T2DM with an emphasis on the application of proteomic technologies.

\section{The beta cell and insulin secretion}

The pancreas is a complex tissue consisting of acinar cells that produce digestive enzymes, duct cells that produce bicarbonate rich fluid, and approximately one million endocrine islets which are distributed through-

${ }^{*}$ Correspondence to: Murray Korc, M.D., Department of Medicine, One Medical Center Drive, Lebanon, NH 03756, USA. Tel.: +1 6036507936 ; Fax: +1 6036506122 ; E-mail: murray.korc@ dartmouth.edu. out the exocrine pancreas, with the greatest density occurring in the tail of the pancreas. The islets are rich in beta cells which secrete insulin, a hormone that is packaged into heterogeneous granules with electrondense cores [1]. In addition, there are adjoining cells in the islets which secrete glucagon (alpha cells) and somatostatin (delta cells), and these hormones counteract insulin's hypoglycemic effects and insulin secretion, respectively. There is also a small population of endocrine cells that secrete pancreatic polypeptide, whose function is not yet fully elucidated.

Small amounts of insulin are secreted from the beta cells in the fasting state, acting to inhibit hepatic gluconeogenesis [2]. Following a meal, glucose enters the beta cell through a process of facilitated diffusion that is mediated by the GLUT-2 glucose transporter. The same glucose transporter is also found in the liver, renal tubules, and the small intestine, but not in other types of islet cells [3]. GLUT-2 exhibits a high $\mathrm{Km}$ for glucose uptake, allowing the beta cell to transport glucose in proportion to the extracellular glucose concentration, thereby leading to a large increase in insulin secretion.

Glucose stimulated release of insulin is biphasic, with a rapid first phase and a more gradual second phase that lasts for two hours and that is partly dependent on the release of newly synthesized insulin [4]. Glucose acts by generating ATP which inhibits a $\mathrm{K}^{+}$channel, thereby depolarizing the beta cell 
plasma membrane, activating voltage-dependent calcium channels, and inducing a rise in intracellular free calcium [5-7]. Calcium-calmodulin protein kinases, cyclic AMP (cAMP)-dependent protein kinases, phosphatidic acid, lysophospholipids, and arachidonic acid and its metabolites also have important roles in modulating insulin secretion [8-10]. Inter- and intracellular signaling by the cells of the pancreatic islet in response to glucose, as well as other metabolites, also contribute to the integrated response of the beta cell and to the controlled release of insulin in response to a meal.

\section{Type 1 diabetes mellitus}

T1DM is characterized by progressive destruction of the beta cells due to the aberrant activation of cellular immune mechanisms, as manifested by the presence of T-cell infiltrates around and within the islets. There are approximately one million T1DM patients in the US, all of whom are dependent on insulin therapy for their survival. The absence of insulin also makes them prone to develop ketoacidosis, a potentially deadly metabolic complication.

The mechanisms that lead to beta cell destruction in T1DM are still not completely understood. It is widely accepted, however, that the selective assault on the beta cell is mediated by cytotoxic T-cells and by certain cytokines [11]. For example, interleukin-1 $\beta$ (IL-1 $\beta$ ) can suppress beta cell function and survival [12]. Proteome based studies of islets and islet derived cell lines that were exposed to IL- $1 \beta$ has revealed a complex pattern of protein alterations, including increased and decreased protein expression and de novo protein induction, underscoring the wide range of responses that can be elicited in the these cells and that can modulate their responsiveness and susceptibility to cytokine mediated cell death [13-15].

In addition to in vitro studies, investigators have addressed the issue of beta cell destruction in numerous in vivo studies. For example, in a recent study with the non-obese diabetic (NOD) mouse, which is an excellent model of T1DM, the Schwann cells that surround the islets were noted to be targeted at an early, pre-diabetic stage by the aberrantly activated $\mathrm{T}$ cells [16]. These peri-islet Schwann cells (pSC) express glial fibrillary acidic protein (GFAP), and the authors noted that the diabetes-prone NOD mice develop pSC-autoreactive $\mathrm{T}$ and $\mathrm{B}$ cell responses that are associated with progressive pSC death that precedes beta cell death. They used surface-enhanced laser des- orption/ionization (SELDI) with time-of-flight (TOF) mass spectrometry to detect auto-antibodies against GFAP in the sera of NOD mice and newly diagnosed diabetic children with T1DM [16]. Thus, an important component of the immune mediated destruction of the beta cell may be mediated by aberrant targeting of pSC.

In another study, peptide epitopes from naturally processed proinsulin were delineated by TOF mass spectrometry, and used to establish very sensitive enzymelinked immunosorbent assays to assess the nature of auto-reactive T-cells in T1DM [17]. These T-cells exhibited a pro-inflammatory Th1 response in T1DM patients, but a T-regulatory cell response leading to the preferential production of the anti-inflammatory cytokine interleukin-10 (IL-10) in non-diabetic individuals [17]. These observations suggest that the immune system actively protects against potential beta cell destruction, and that this protective mechanism is lost in T1DM.

\section{Type 2 diabetes mellitus}

T2DM is characterized by insulin resistance, a failure of the beta cell to produce enough insulin to overcome the resistance, inappropriate hepatic glucose release, and production of cytokines by adipose tissue that interfere with insulin action. There are approximately 16 million T2DM patients in the US, some of whom may require insulin therapy to achieve adequate blood glucose control. The presence of normal, increased, or slightly decreased circulating insulin levels assures that they only rarely develop ketoacidosis.

Insulin resistance in T2DM may be the consequence of abnormal production of anti-insulin receptor antibodies [18], but is generally due to post-receptor defects [19]. Some examples of post-receptor defects include silent polymorphisms and naturally occurring amino acid substitutions in the insulin receptor substrate-1 (IRS-1) signaling protein which may contribute to insulin resistance [20,21]. In support of this hypothesis, IRS-1 knockout mice exhibit insulin resistance and glucose intolerance [22], and IRS2 knockout mice exhibit decreased insulin-stimulated glucose transport in conjunction with decreased beta cell mass and overt diabetes [23]. Similarly, there is homology between the ataxia-telangiectasia (AT) gene product and phosphatidylinositol 3-kinase (PI 3kinase). The relatively high frequency of T2DM in patients with AT raises the possibility that perturbations in PI 3-kinase function may represent one of the post- 
receptor defects that contributes to insulin resistance in some T2DM [24]. Mutations in the peroxisome proliferator-activated receptor (PPAR $\gamma$ ) may lead to altered adipocyte differentiation and energy storage and may also contribute to insulin resistance in T2DM [25]. Furthermore, excessive secretion of certain hormones such as cortisol, as seen in Cushing's disease, or growth hormone, as seen in acromegaly, may antagonize insulin action sufficiently to induce a T2DM-like state.

T2DM is often associated with obesity, which is a major cause for insulin resistance. Increased visceral obesity is especially deleterious in this regard because visceral fat is prone to release free fatty acids (FFA) which directly interfere with efficient insulin signaling, partly as a result of enhanced protein kinase $\mathrm{C}$ isoforms activity and increased hepatic glucose release [26,27]. Furthermore, visceral fat expresses the $\beta 3$-adrenergic receptor, which participates in the regulation of thermogenesis and lipolysis [28], and mutations in this receptor are associated with insulin resistance, an earlier onset of T2DM and attenuated insulin secretion [29, 30]. The adipocyte is also the source of several cytokines such as tumor necrosis factor alpha (TNF- $\alpha$ ), which induces insulin resistance by down-regulating GLUT4 and increasing free fatty acid release [31], and interleukin-6 (IL-6), which induces insulin resistance in fat cells and hepatocytes [32,33]. By contrast, adiponectin and IL-10 exert anti-diabetogenic effects $[34,35]$, and reduced levels of IL-10 increase the risk for the development of the dysmetabolic syndrome in women [36]. In addition to obesity and diabetes, patients with the dysmetabolic syndrome exhibit hypertension, hyperlipidemia, heart disease and peripheral vascular disease, and a tendency towards elevated uric acid levels.

The role of adipose tissue in the pathogenesis of insulin resistance has been investigated in several model cell lines, including the mouse 3T3-L1 fibroblastic cell line which differentiates rapidly into an adipocyte phenotype in response to insulin and is useful, therefore, for studying insulin action and adipogenic differentiation. Thus, two-dimensional gel electrophoresis of 3T3-L1 cell lysates revealed that insulin does not stimulate calmodulin phosphorylation under conditions in which it stimulates the phosphorylation of other proteins [37], and indicated that altered expression of several cellular proteins contributes to the differentiation process in these cells [38]. More recently, a proteome based approach using velocity gradient centrifugation to achieve the initial separation of proteins revealed that there was a marked increase in mitochondrial proteins in these cells during the differentiation process [39]. The authors also examined the effects of rosiglitazone, an agonist that activates the gamma isoform of the peroxisome proliferator-activated receptor $(\operatorname{PPAR} \gamma)$, which is a nuclear receptor that modulates adipocyte differentiation. In addition to altering mitochondrial morphology, rosiglitazone increased the levels of proteins involved in fatty acid oxidation, such as acyl-CoA synthetase and dehydrogenase [40]. Rosiglitazone also increases carboxypeptidase B expression in mouse islets [41], and modulates components of the peroxisomal fatty acid metabolism pathway in adipose tissue [42], raising the possibility that it may also ameliorate glucose homeostasis by improving insulin processing and fatty acid metabolism.

Another site of insulin resistance is the skeletal muscle. A proteome based analysis of human skeletal muscle identified 8 potential markers of T2DM [43]. The levels of two proteins that have a crucial role in ATP synthesis, creatine kinase B and ATP synthase $\beta$ subunit, were decreased in the muscle tissue of T2DM patients. Genetic muscular disorders may also be associated with a high incidence of T2DM. For example, patients with mitochondrial myopathies may present with muscle weakness, symmetric paralysis of the extraocular muscles, drooping eyelids (ptosis), T2DM and cardiomyopathy [44]. Other patients with T2DM exhibit a maternal pattern of inheritance in conjunction with inherited deafness and mitochondrial gene defects [45]. The importance of mitochondrial defects in T2DM was highlighted in a recent study which revealed that insulin-resistant children of T2DM parents exhibited increased muscle cell lipid content in conjunction with decreased mitochondrial phosphorylation, as determined by magnetic resonance spectroscopy [46]. Interestingly, rates of lipolysis and plasma levels of IL-6, TNF-a, and adiponectin were not different in the two groups, further underscoring the potential importance of the mitochondrial defect in the pathogenesis of insulin resistance.

Disorders of the pancreas that are neither T1DM nor T2DM may also be associated with glucose intolerance and diabetes. These include chronic pancreatitis, cystic fibrosis, pancreatic cancer, sequelae of partial pancreatectomy, hemochromatosis, and transfusion associated iron overload. It has been suggested that increased iron stores in general may lead to an increased propensity to T2DM [47], and that both chronic pancreatitis and pancreatic cancer may be associated with a significant component of insulin resistance that contributes to the hyperglycemia that may occur in these conditions [48, 
49]. Future proteome based studies in these conditions may therefore shed new light on novel mechanisms for insulin resistance.

\section{Conclusion}

T1DM is caused by immune mediated beta cell destruction. T2DM is caused by insulin resistance in conjunction with variable degrees of a defective beta cell response to hyperglycemia [50]. Proteome based studies are likely to yield additional insight into the mechanisms involved in pathophysiology of both disorders. Already, proteome based studies are contributing information about beta cell responses to insulin treatment and to inflammatory cytokines, as well as potential biomarkers of T2DM in skeletal muscle.

\section{References}

[1] S. Falkmer and Y. Ostberg, Comparative morphology of pancreatic islets in animals, in: The Diabetic Pancreas, B.M. Volk and K.F. Wellman eds., Plenum Press, New York, 1977, pp. 15-60.

[2] D.A. Lang, D.R. Matthews, J. Peto and R.C. Turner, Cyclic oscillations of basal plasma glucose and insulin concentrations in human beings, New. Engl. J. Med. 301 (1979), 1023-1027.

[3] A.L. Olson and J.E. Pessin, Structure, function, and regulation of the mammalian facilitative glucose transporter gene family, Annu. Rev. Nutr. 16 (1996), 235-256.

[4] J.C. Henquin, N. Ishiyama, M. Nenquin, M.A. Ravier and J.C. Jonas, Signals and pools underlying biphasic insulin secretion, Diabetes 51 (2002), S60-67.

[5] D.L. Cook and C.N. Hales, Intracellular ATP directly blocks $\mathrm{K}^{+}$channels in pancreatic -cells, Nature 311 (1984), 271-273.

[6] S.W. Chouinard, F. Lu, B. Ganetzky and M.J. MacDonald, Evidence for voltage-gated potassium channel $\beta$-subunits with oxidoreductase motifs in human and rodent pancreatic betacells, Receptor Channels 7 (2000), 237-243.

[7] H. Kindmark, M. Köhler, G. Brown, R. Bränsträm, O. Larsson and P.O. Berggren, Glucose-induced oscillations in cytoplasmic free $\mathrm{Ca}^{2+}$ concentration precede oscillations in mitochondrial membrane potential in the pancreatic-cel1, J. Biol. Chem. 276 (2001), 30-36.

[8] M. Prentki, New insights into pancreatic beta-cell metabolic signaling in insulin secretion, Eur. J. Endocrinol. 134 (1996), 272-286.

[9] R.A. Easom, CaM kinase II: a protein kinase with extraordinary talents germane to insulin exocytosis, Diabetes 48 (1999), $675-684$.

[10] J.T. Lawrence and M.J. Birnbaum, ADP-ribosylation factor 6 regulates insulin secretion through plasma membrane phosphatidylinositol 4,5-bisphosphate, Proc. Natl. Acad. Sci. USA 100 (2003), 13320-13325.

[11] A. Rabinovitch and W.L. Suarez-Pinzon, Role of cytokines in the pathogenesis of autoimmune diabetes mellitus, Rev. Endocr. Metab. Disord. 4 (2003), 291-299.
[12] T. Mandrup-Poulsen, Beta cell death and protection, Ann. N.Y. Acad. Sci. 1005 (2003), 32-42.

[13] N.E. John, H.U. Andersen, S.J. Fey, P.M. Larsen, P. Roepstorff, M.R. Larsen, F. Pociot, A.E. Karlsen, J. Nerup, I.C. Green and T. Mandrup-Poulsen, Cytokine- or chemically derived nitric oxide alters the expression of proteins detected by two-dimensional gel electrophoresis in neonatal rat islets of Langerhan, Diabetes 49 (2000), 1819-1829.

[14] P.M. Larsen, S.J. Fey, M.R. Larsen, A. Nawrocki, H.U. Andersen, H. Kahler, C. Heilmann, M.C. Voss, P. Roepstorff, F. Pociot, A.E. Karlsen and J. Nerup, Proteome analysis of interleukin-1beta-induced changes in protein expression in rat islets of Langerhans, Diabetes 50 (2001), 1056-1063.

[15] K. Nielsen, T. Sparre, M.R. Larsen, M. Nielsen, S.J. Fey, P. Mose Larsen, P. Roepstorff, J. Nerup and A.E. Karlsen, Protein expression changes in a cell system of beta-cell maturation reflect an acquired sensitivity to IL-1beta, Diabetologia 47 (2004), 62-74.

16] S. Winer, H. Tsui, A. Lau, A. Song, X. Li, R.K. Cheung, A. Sampson, F. Afifiyan, A. Elford, G. Jackowski, D.J. Becker, P. Santamaria, P. Ohashi and H.M. Dosch, Autoimmune islet destruction in spontaneous type 1 diabetes is not beta-cell exclusive, Nat. Med. 9 (2003), 198-205.

[17] S. Arif, T.I. Tree, T.P. Astill, J.M. Tremble, A.J. Bishop, C.M. Dayan, B.O. Roep and M. Peakman, Autoreactive T cell responses show proinflammatory polarization in diabetes but a regulatory phenotype in health, J. Clin. Invest. 113 (2004), 451-463.

[18] E. Arioglu, A. Andewelt, C. Diabo, M. Bell, S.I. Taylor and P. Gorden, Clinical course of the syndrome of autoantibodies to the insulin receptor (type B insulin resistance): a 28-year perspective, Medicine (Baltimore) 81 (2002), 87-100.

[19] S.C. Elbein, Perspective: the search for genes for type 2 diabetes in the post-genome era, Endocrinology 143 (2002), 2012-2018.

[20] Y. Imai, N. Philippe, G. Sesti, D. Accili and S.I. Taylor, Expression of variant forms of insulin receptor substrate-1 identified in patients with noninsulin-dependent diabetes mellitus, J. Clin. Endocrinol. Metab. 82 (1997), 4201-4207.

[21] D.L. Esposito, Y. Li, C. Vanni, S. Mammarella, S. Veschi, F. Della Loggia, R. Mariani-Costantini, P. Battista, M.J. Quon and A. Cama, A novel T608R missense mutation in insulin receptor substrate-1 identified in a subject with type 2 diabetes impairs metabolic insulin signaling, J. Clin. Endocrinol. Metab. 88 (2003), 1468-1475.

[22] E. Araki, M.A. Lipes, M.E. Patti, J.C. Bruning, B. Haag 3rd, R.S. Johnson and C.R. Kahn, Alternative pathway of insulin signalling in mice with targeted disruption of the IRS-1 gene, Nature 372 (1994), 186-190.

[23] D.J. Withers, J.S. Gutierrez, H. Towery, D.J. Burks, J.M. Ren, S. Previs, Y. Zhang, D. Bernal, S. Pons, G.I. Shulman, S. Bonner-Weir and M.F. White, Disruption of IRS-2 causes type 2 diabetes in mice, Nature 391 (1998), 900-904.

[24] K. Savitsky, A. Bar-Shira, S. Gilad, G. Rotman, Y. Ziv, L. Vanagaite, D.A. Tagle, S. Smith, T. Uziel and S. Sfez, A single ataxia telangiectasia gene with a product similar to PI-3 kinase, Science 268 (1995), 1749-1753.

[25] R. Rosmond, M. Chagnon and C. Bouchard, The Pro12Ala PPARgamma2 gene missense mutation is associated with obesity and insulin resistance in Swedish middle-aged men, Diabetes Metab. Res. Rev. 19 (2003), 159-163.

[26] G. Boden, Interaction between free fatty acids and glucose metabolism, Curr. Opin. Clin. Nutr. Metab. Care 5 (2002), 545-549. 
[27] T.K. Lam, A. Carpentier, G.F. Lewis, G. Van De Werve, I.G. Fantus and A. Giacca, Mechanisms of the free fatty acidinduced increase in hepatic glucose production, Am. J. Physiol. Endocrinol. Metab. 284 (2003), E863-873.

[28] M. Griffiths, P.R. Payne, A.J. Stunkard, J.P. Rivers and M. Cox, Metabolic rate and physical development in children at risk of obesity, Lancet 336 (1990), 76-78.

[29] J. Walston, K. Silver, C. Bogardus, W.C. Knowler, F.S. Celi, S. Austin, B. Manning, A.D. Strosberg, M.P. Stern, N. Raben, J.D. Sorkin, J. Roth and A.R. Shuldiner, Time of onset of non-insulin-dependent diabetes mellitus and genetic variation in the beta 3-adrenergic-receptor gene, $N$. Engl. J. Med. $\mathbf{3 3 3}$ (1995), 343-347.

[30] J. Walston, K. Silver, H. Hilfiker, R.E. Andersen, M. Seibert, B. Beamer, J. Roth, E. Poehlman and A.R. Shuldiner, Insulin response to glucose is lower in individuals homozygous for the Arg 64 variant of the beta-3-adrenergic receptor, J. Clin. Endocrinol. Metab. 85 (2000), 4019-4022.

[31] P. Peraldi and B. Spiegelman, TNF-alpha and insulin resistance: summary and future prospects, Mol. Cell. Biochem. 182 (1998), 169-175.

[32] V. Rotter, I. Nagaev and U. Smith, Interleukin-6 (IL-6) induces insulin resistance in 3T3-L1 adipocytes and is, like IL-8 and tumor necrosis factor-alpha, overexpressed in human fat cells from insulin-resistant subjects, J. Biol. Chem. 278 (2003), $45777-45784$

[33] P.J. Klover, T.A. Zimmers, L.G. Koniaris and R.A. Mooney, Chronic exposure to interleukin-6 causes hepatic insulin resistance in mice, Diabetes 52 (2003), 2784-2789.

[34] C. Weyer, T. Funahashi, S. Tanaka, K. Hotta, Y. Matsuzawa, R.E. Pratley and P.A. Tataranni, Hypoadiponectinemia in obesity and type 2 diabetes: close association with insulin resistance and hyperinsulinemia, J. Clin. Endocrinol. Metab. 86 (2001), 1930-1935.

[35] E. van Exel, J. Gussekloo, A.J. de Craen, M. Frolich, A. Bootsma-Van Der Wiel and R.G. Westendorp, Leiden 85 Plus Study. Low production capacity of interleukin-10 associates with the metabolic syndrome and type 2 diabetes: the Leiden 85-Plus Study, Diabetes 51 (2002), 1088-1092.

[36] K. Esposito, A. Pontillo, F. Giugliano, G. Giugliano, R. Marfella, G. Nicoletti and D. Giugliano, Association of low interleukin-10 levels with the metabolic syndrome in obese women, J. Clin. Endocrinol. Metab. 88 (2003), 1055-1058.

[37] P.J. Blackshear and D.M. Haupt, Evidence against insulinstimulated phosphorylation of calmodulin in 3T3-L1 adipocytes, J. Biol. Chem. 264 (1989), 3854-3858.

[38] H.B. Sadowski, T.T. Wheeler and D.A. Young, Characterization of initial responses to the inducing agents and changes during commitment to differentiation, J. Biol. Chem. 267 (1992), $4722-4731$.
[39] L. Wilson-Fritch, A. Burkart, G. Bell, K. Mendelson, J. Leszyk, S. Nicoloro, M. Czech and S. Corvera, Mitochondrial biogenesis and remodeling during adipogenesis and in response to the insulin sensitizer rosiglitazone, Mol. Cell Biol. 23 (2003), 1085-1094.

[40] U. Edvardsson, H. Brockenhuus Von Lowenhielm, O. Panfilov, A.C. Nystrom, F. Nilsson and B. Dahllof, Hepatic protein expression of lean mice and obese diabetic mice treated with peroxisome proliferator-activated receptor activators, Proteomics 3 (2003), 468-478.

[41] J.C. Sanchez, V. Converset, A. Nolan, G. Schmid, S. Wang, M. Heller, M.V. Sennitt, D.F. Hochstrasser and M.A. Cawthorne, Effect of rosiglitazone on the differential expression of diabetes-associated proteins in pancreatic islets of C57B1/6 lep/lep mice, Mol. Cell Proteomics. 1 (2002), 509-516.

[42] U. Edvardsson, M. Bergstrom, M. Alexandersson, K. Bamberg, B. Ljung and B. Dahllof, Rosiglitazone (BRL49653), a PPARgamma-selective agonist, causes peroxisome proliferator-like liver effects in obese mice, J. Lipid Res. 40 (1999), 1177-1184.

[43] K. Hojlund, K. Wrzesinski, P.M. Larsen, S.J. Fey, P. Roepstorff, A. Handberg, F. Dela, J. Vinten, J.G. McCormack, C. Reynet and H. Beck-Nielsen, Proteome analysis reveals phosphorylation of ATP synthase beta -subunit in human skeletal muscle and proteins with potential roles in type 2 diabetes, $J$. Biol. Chem. 278 (2003), 10436-10442.

[44] D.K. Simon and D.R. Johns, Mitochondrial disorders: clinical and genetic features, Anпи. Rev. Med. 50 (1999), 111-127.

[45] J.A. Maassen, Mitochondrial diabetes: pathophysiology, clinical presentation, and genetic analysis, Am. J. Med. Genet. 115 (2002), 66-70.

[46] K.F. Petersen, S. Dufour, D. Befroy, R. Garcia and G.I. Shulman, Impaired mitochondrial activity in the insulin-resistant offspring of patients with type 2 diabetes, N. Engl. J. Med. 350 (2004), 664-671.

[47] J.G. Wilson, J.H. Lindquist, S.C. Grambow, E.D. Crook and J.F. Maher, Potential role of increased iron stores in diabetes, Am. J. Med. Sci. 325 (2003), 332-339.

[48] G. Cavallini, B. Vaona, P. Bovo, M. Cigolini, L. Rigo, F. Rossi, E. Tasini, M.P. Brunori, V. Di Francesco and L. Frulloni, Diabetes in chronic alcoholic pancreatitis. Role of residual beta cell function and insulin resistance, Dig. Dis. Sci. 38 (1993), 497-501.

[49] F. Wang, M. Herrington, J. Larsson and J. Permert, The relationship between diabetes and pancreatic cancer, Mol. Cancer 2 (2003), 1-5.

[50] S.E. Kahn, The relative contributions of insulin resistance and beta-cell dysfunction to the pathophysiology of Type 2 diabetes, Diabetologia 46 (2003), 3-19. 


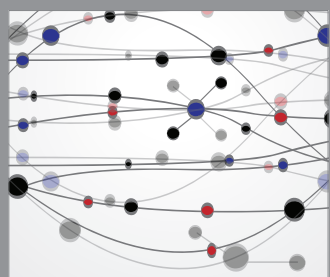

The Scientific World Journal
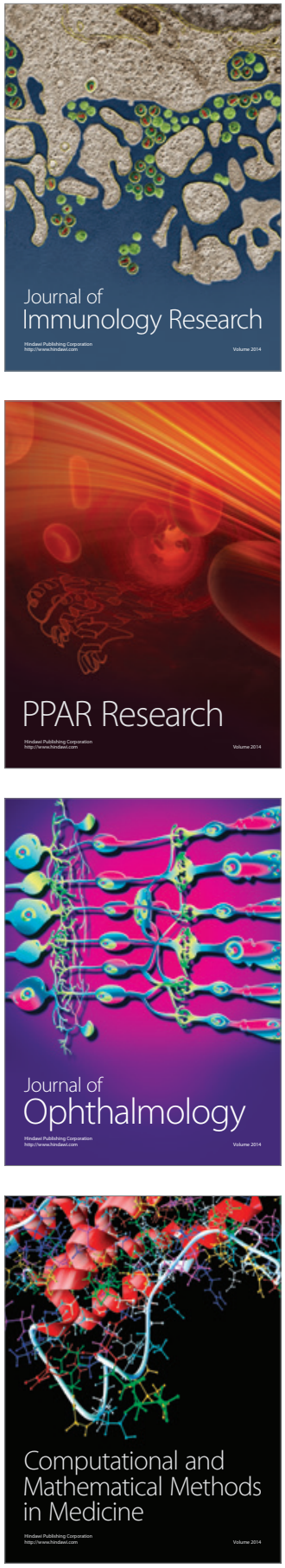

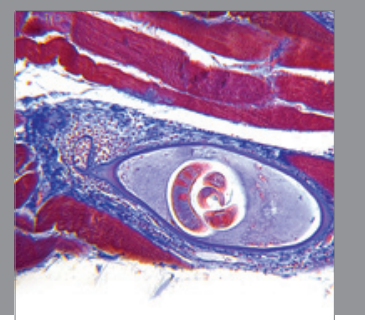

Gastroenterology

Research and Practice
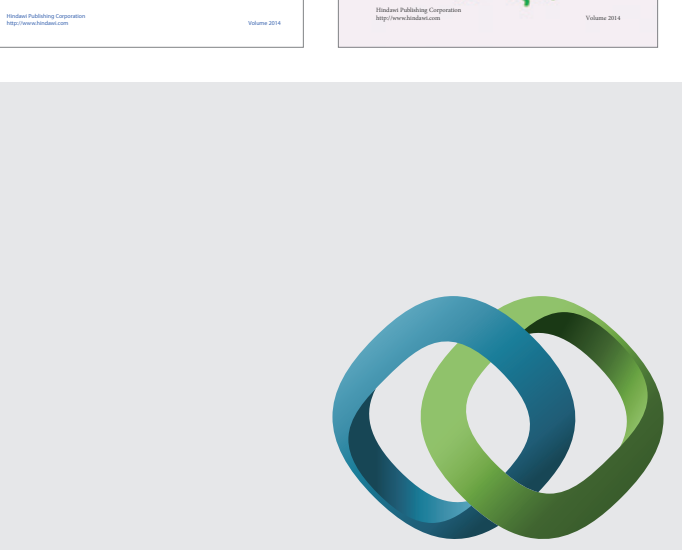

\section{Hindawi}

Submit your manuscripts at

http://www.hindawi.com
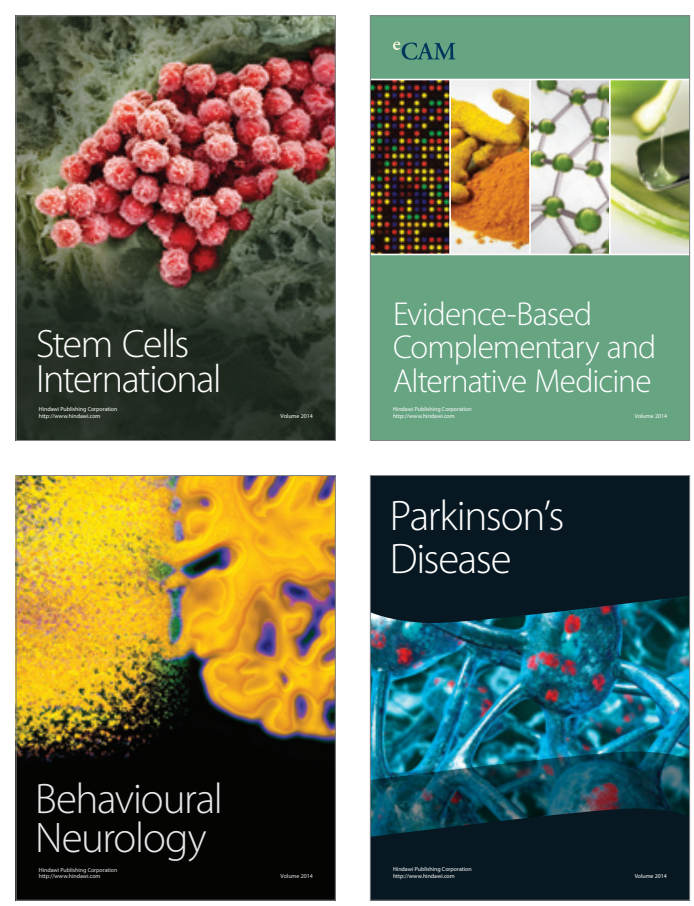

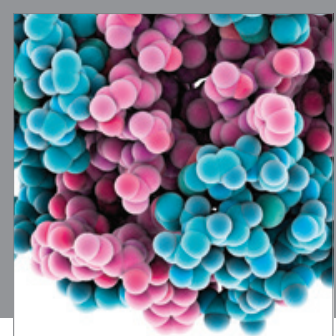

Journal of
Diabetes Research

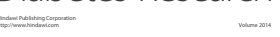

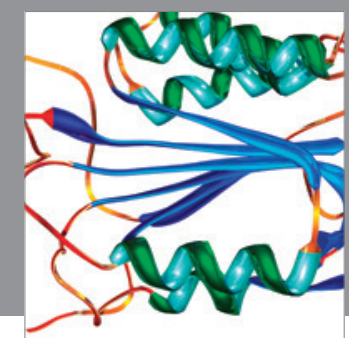

Disease Markers
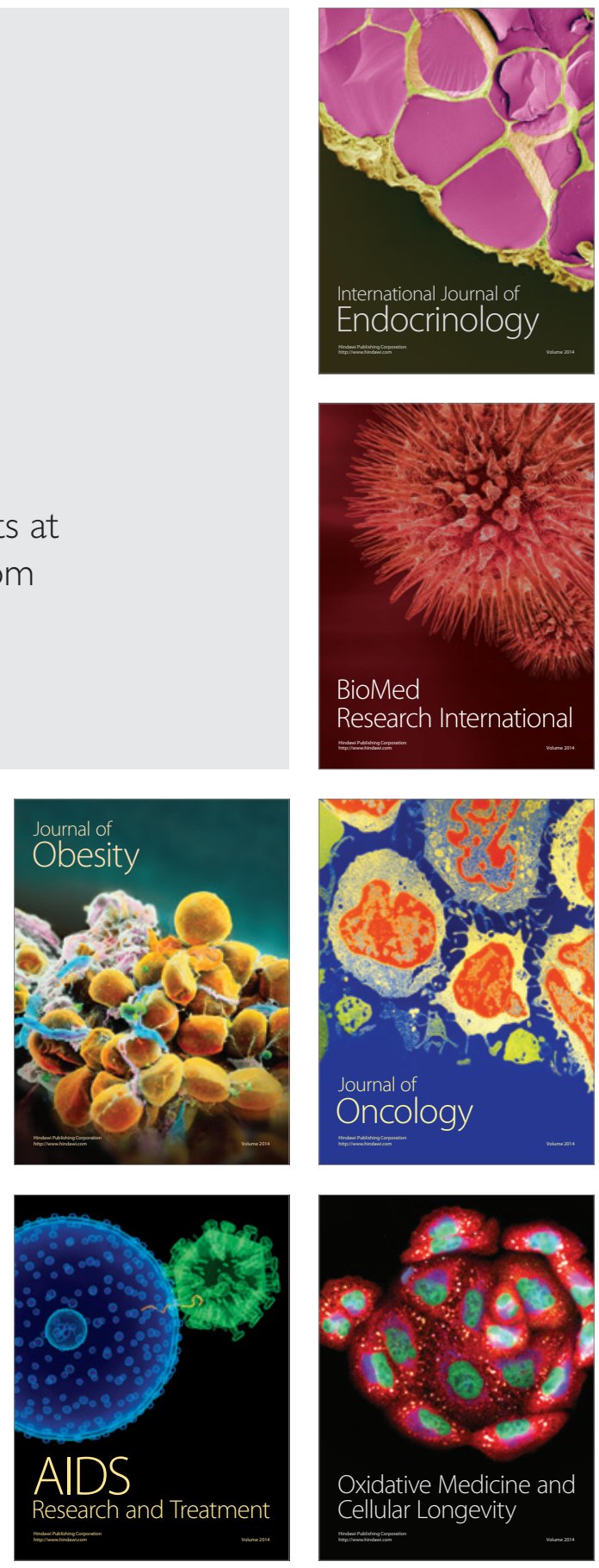